\title{
A representação audiovisual do real a partir de uma abordagem das falas dos personagens
}

\author{
THE AUDIOVISUAL REPRESENTATION OF REALITY BASED ON THE ANALYSIS \\ OF THE CHARACTERS' SPEECH
}

\section{Fernando Andacht}

Chefe do departamento de Teoria e Metodologia da Faculdade de Informação e Comunicação, Universidad de la República, Montevidéu, Uruguai. Professor colaborador da Universidade Tuiuti do Paraná, Brasil.

E-mail: fernando.andacht@fic.edu.uy

\section{Débora Regina Opolski}

Professora da Universidade Federal do Paraná. Doutoranda da Universidade Tuiuti do Paraná.

E-mail: deboraopolski@gmail.com

Recebido em 6 de abril de 2016. Aprovado em 19 de setembro de 2016.

\section{Resumo}

Este artigo apresenta quatro aspectos da abordagem do real: a representação do real na mídia; diversas concepções de representação; o mecanismo de representação e a continuidade entre o real e seus signos, conforme uma análise baseada na semiótica de C. S. Peirce. Para discutir a contribuição da fala dos personagens para representar o real, propõe-se uma análise que aborda esse tipo de representação a partir dos diálogos de personagens da série televisual e do filme Cidade dos homens.

Palavras-chave: Fala no cinema/televisão. Semiótica. Representação do real.

\section{Abstract}

This article presents four aspects of the analysis of reality: the media representation of reality, different conceptions of representation; the mechanism of representation; and the continuity between reality and its signs, according to an analysis based on the semiotic of C. S. Peirce. To discuss the contribution of the characters' speech to represent reality, we propose an analysis that approaches this kind of representation in dialogues of fictional characters from the TV series and film Cidade dos homens.

Keywords: Speech in film/television. Semiotics. Representation of reality. 


\section{Introdução}

"Filmes que parecem ou que são experimentados como se fossem documentários são muito mais numerosos, e muito mais desconcertantes, especialmente a partir do momento no qual a quase-verdade (truthiness) tem virado o enquadramento por defeito de tantas mídias" (SCOTT, 2010).

O comentário que inicia um artigo do chefe dos críticos do The New York Times é um sintoma da atualidade, um signo do Zeitgeist contemporâneo, que se pode chamar o fascínio irresistível do real - ou pegando carona da reflexão do crítico de cinema, de tudo aquilo que se assemelha bastante ao real. Quando se fala "real" no âmbito acadêmico da comunicação, mais especificamente do estudo do audiovisual, esse termo vem acompanhado daquilo que uma visão construtivista radical considera ser o inimigo máximo do real, qual seja, a representação.

Este texto faz uma abordagem diferente, porque não pretende aprofundar a velha discussão filosófica sobre a confusão ou falta de limite entre o real e a ficção, concebida esta última como uma gigantesca ilusão ou engano coletivo - cujo antecedente mais ilustre é a caverna do Platão. Mais perto da mimese fílmica, da tecnologia da representação e de outro conceito grego tão antigo como o das ilusões platônicas, nossa abordagem analisa um mecanismo de sentido muito próximo do corpo e de suas circunstâncias, de seu efeito no realismo no cinema e na televisão brasileira atual, relacionando esse efeito com a representação do contexto urbano da contemporaneidade.

A pergunta relaciona-se com algo básico mas ainda pouco explorado nos estudos de cinema e de televisão: de que forma o jeito de falar dos atores de produções como Cidade dos homens ${ }^{1}$ se relaciona com o ambiente urbano? É relevante que os atores das criações audiovisuais analisadas provenham da favela, que seu jeito de falar seja um indício notório de que a vida deles, uma parte ao menos, desenvolveu-se lá, no espaço representado por uma ficção como $C D H$ ?

Para responder a essa pergunta, usamos como teoria o modelo triádico da significação de Peirce; o pensador americano não limitou sua pesquisa aos signos verbais, à fala, mas incluiu nela os signos não verbais ou índices; essa espécie de sombra ou de suor semiótico que acompanha tudo o que se diz, qual seja, os gestos, o tom, as pegadas da origem social e individual do falante. Assim, a representação do real nessas produções audiovisuais inclui como componente central a língua portuguesa, mas

1 Série televisiva (2002-2005) produzida por O2 Filmes e Globo Vídeo. Vários diretores. Filme (2007) Produzido por O2 Filmes. Dirigido por Paulo Morelli. Doravante referidos como $C D H$. 
também as evidências sonoras de pertença material, biográfica a um mundo específico e problemático na sociedade brasileira.

\section{O verossímil e o real cinematográfico}

Metz (2007) traça um breve panorama histórico para demonstrar que o verossímil "é uma redução do possível" (p. 229); é um tipo de discurso apresentado a um grupo através de censuras e regras preestabelecidas, sendo uma restrição arbitrária "entre os possíveis reais" (loc. cit.). Para Aristóteles, o verossímil dizia respeito ao senso comum; era verossímil o que fosse "possível aos olhos do senso comum" (Ibid., p. 228). Já o século 17 compreende o verossímil como "o que está conforme as regras de um gênero estabelecido" (Ibid., p. 229).

No entanto, Metz deixa claro que as variações de acordo com local, época, estilo, censura, arbitrariedades etc. alteram o "conteúdo dos verossímeis, não o estatuto de verossímil”" (Ibid., p. 235). Ou seja, alteram as convenções específicas compartilhadas pelo grupo do que seria verossímil de acordo com o momento histórico e com o local considerado. Segundo o autor, uma das opções para escapar do verossímil acontece com a chegada de um discurso novo, que abre um espaço inédito ao real; a outra opção surge da "verdade de um código livremente assumido", qual seja, "os verdadeiros filmes de gênero" (Ibid., p. 242), que não se preocupam em ocultar suas convenções bem estabelecidas conforme a estética cinematográfica escolhida, por exemplo, o western ou o policial americanos.

Dessa perspectiva, a busca pela verdade absoluta, fora dos códigos do cinema, é uma idealização, ao passo que a linguagem, verbal ou não verbal, vive e se desenvolve em dois âmbitos: a instituição cinematográfica e a realidade exterior. O real exterior é tudo o que fica fora do cinema, e nesse caso, existem elementos possíveis do real externo que ainda não fazem parte do verossímil fílmico e, portanto, são "infinitamente difíceis de traduzir" (Ibid., p. 236), isto é, de se transpor ao discurso aceitável de uma ficção comercial como $C D H$.

Assumindo a posição de busca pelo real do acontecimento registrado, surge a questão do ato de filmagem como uma interferência direta no material registrado. $\mathrm{O}$ real cinematográfico é questionado: "é real a realidade registrada em imagens e sons, e, ainda mais, depois de ser interpretada pelo realizador?” (ANDACHT, 2007, p. 43). É possível que a estética ou o aparato cinematográfico influenciem no material gravado a ponto de que tanto um fato filmado quanto uma encenação se transformem em ficção? (Ibid.).

Quando as questões envolvidas no processo de realização do filme são consideradas como um agente perturbador, um documentário é visto como uma alteração da realidade, como uma realidade fabricada. Há um antecedente filosófico na afirmação de 
William James (1907) de que a realidade é transformada, peptonizada por um pensamento anterior, pelo fato de o real ser representado: "podemos vislumbrar [a realidade] mas nunca a alcançamos” (p. 95-96). Tal concepção supõe que não é possível estar diante da realidade, pois ela é sempre "falsificada" [faked] pela sua representação.

No entanto, do ponto de vista semiótico, a filmagem é um signo cuja função é revelar de modo falível e incompleto algo sobre alguma coisa - nesse caso, algo do mundo que existe e que continuaria existindo mesmo se não fosse filmado. Se usarmos o modelo semiótico de Peirce (CP 5.283)², é possível analisar um filme ou uma série de TV a partir dos signos escolhidos para produzir e interpretar o audiovisual, pois são influenciados tanto pelo universo discursivo - a intertextualidade, o gênero, o cânon fílmico quanto pelo âmbito do real que se procura representar de modo naturalista, por exemplo. Portanto, o que o audiovisual apresenta é a representação de uma relação que pode estar permeada por verdades ou mentiras, mas isso independe do aparato cinematográfico, ou da filmagem, pois "afirmações verdadeiras e também mentiras acontecem sempre que há atividade sígnica" (ANDACHT, 2007, p. 46), seja verbal ou não verbal.

Para nos afastar de um pensamento dicotômico e reducionista para o qual tudo é real ou tudo é ficção, serve a concepção da realidade elaborada por Peirce, na qual tudo o que aparece e parece alguma coisa perante nós é ao mesmo tempo a manifestação fenomênica de nossa própria existência, isto é, o resultado dos limites de nossa percepção do mundo, aquilo que os cinco sentidos trazem, junto ao nosso conhecimento do mundo, mas também de algo que é externo a nós, que é independente daquilo que possamos pensar a respeito (CP 5.283). Essa simultaneidade do funcionamento dos signos é fundamental para compreender o realismo documentário e o neorrealismo de uma série ficcional ancorada narrativamente num entorno real - o espaço é um dos protagonistas da história - reconhecível por muitas pessoas como a ecologia cotidiana dos marginalizados de um lugar específico e concreto do mundo.

$\mathrm{O}$ fato de uma minissérie e de um filme serem encenados num lugar real, nesse caso, em uma favela carioca, não faz com que essas produções audiovisuais sejam menos ficcionais, e que seus personagens e o enredo que governa seus comportamentos não sejam o produto da imaginação do roteirista. Porém, há algo duro como uma pedra no fato de os atores pertencerem a esse espaço e falar como as pessoas que realmente moram (ou moravam) lá. Isso é o que acontece na série e no filme $C D H^{3}$.

2 A obra de Peirce será referenciada do modo convencional: x.xxx, o qual se refere ao volume e parágrafo da edição de The Collected Papers of C. S. Peirce (1931-1958).

3 Os atores principais de $C D H$, além de terem nascido no morro do Vidigal, não conheceram os próprios pais, assim como os personagens por eles interpretados. De acordo com Paulo Morelli, houve uma preocupação por parte da equipe de produção do filme e uma conversa prévia com os atores para saber como seria trabalhar 
Peirce ilustra a concepção continuísta, não dualista, do papel dos signos no conhecimento do mundo real e imaginário e também de nós mesmos, através do fenômeno meteorológico do arco-íris: nossas representações do mundo se assemelham à manifestação do sol e da chuva (CP 5.283): estas possuem necessariamente um elemento subjetivo, próprio de nossa forma humana de experimentar o mundo (que inclui elementos linguísticos, visuais, auditivos etc.), de tudo o que conhecemos, mas também de um elemento externo, de algo que provém da realidade que nos rodeia e que não podemos controlar.

\section{Representação do real na mídia}

Baseado no princípio de continuidade lógica ou sinequismo de Peirce (CP 1.172), pode-se argumentar que não há uma separação absoluta entre a realidade e suas múltiplas classes de representação, pois o único modo possível de conhecer o mundo, o real, quer na vida ou num filme, é justamente pelos signos ou representações. Tanto no cinema quanto em outros meios de comunicação, toda representação é a priori falível e incompleta, isto é, pode estar errada ou ser falsa, e necessariamente deve excluir muitos aspectos do real representado, aqueles não selecionados para poder comunicar algo específico.

O real fora de toda representação chama-se "objeto dinâmico"4, aquilo que é representado parcialmente; o signo é o meio que apresenta algum aspecto desse real, "o representamen" (CP 1.480). A relação entre o objeto dinâmico e o representamen produz as três classes mais conhecidas de signos, quais sejam, "o ícone, o índice e o símbolo" (CP 2.303-308). Para a semiótica peirceana, toda realidade gera alguma classe de representação e, como tal, pode ser analisada a partir daquela tríade: as dimensões qualitativa, factual e geral da realidade, respectivamente.

Em dois ensaios, o crítico de cinema do The New York Times, A. O. Scott ${ }^{5}$, reflete sobre o significado da noção de realismo nessa época. Sobre a atual proliferação de filmes que se apresentam como "realistas" ou relacionados com o real, Scott comenta: "Atualmente, porém, a realidade está em todo lugar que você observe, e ela adota formas vertiginosamente protéicas” (2015, tradução nossa). Com ironia, Scott fala também da

e interpretar um tema delicado e vivenciado por ambos os atores (INSTITUTO HUMANITAS UNISINOS, 2007). Além dos personagens principais, Jonathan Haagensen, que interpreta o Madrugadão no filme, e Roberta Rodrigues, que interpreta a Poderosa na série, também foram moradores do morro do Vidigal, com passagem pelo projeto Nós do morro (projeto que oferece atividades de teatro e de cinema para os moradores - cf.: <http://www.nosdomorro.com.br/>).

4 "O objeto dinâmico é a realidade que por algum meio consegue determinar o signo para sua representação" (CP 4.536).

5 "How real does it feel?" (9 dez. 2010) e “"True Story," 'The Jinx' and serving up truth with the imagination" (22 abr. 2015). 
"atração infindável da vertigem epistemológica" (Ibid.), em referência às discussões acirradas dos críticos e do público sobre a eventual veracidade dos fatos representados em filmes baseados em episódios reais e em documentários.

Esses dois ensaios tentam abranger um objeto mais amplo do que o filme concreto que o crítico escolhe a cada semana; eles são sintomáticos do fato de a representação do real ser um fenômeno constantemente presente na produção cinematográfica atual. Trata-se de um real explícito, tematizado, tão importante quanto duvidoso, que funciona como uma possível garantia de interesse no público, mas também como risco calculado da suspeita desse mesmo público sobre seu caráter autêntico ou artificial, fabricado para atrair espectadores.

Podemos perceber tal presença através da forma de falar dos personagens. De acordo com Kozloff (2000), desde 1927, houve uma mudança progressiva no diálogo cinematográfico, com o objetivo de atingir o realismo na fala: "um movimento em direção ao realismo, em direção ao mais coloquial, estilo naturalístico" (p. 24). Essa tendência teve um longo percurso, que começou com o estabelecimento de uma norma-padrão para a fala, denominada "dicção transatlântica" em Hollywood (LEITCH, 2013). Essa forma de falar tinha o objetivo de unificar a expressão. O mesmo aconteceu no Brasil com o estabelecimento do "sotaque branco". "Transatlântico" e "branco" são duas palavras que remetem a algo que não seja marcado por nenhum regionalismo e que, portanto, seja compreendido por todos os espectadores.

No final da década de 1930, o rádio aparece como uma forte influência na fala cinematográfica. Para Leitch, houve um programa nos Estados Unidos denominado Amos ' $n$ ' Andy, no qual dois atores representavam vocalmente 170 personagens, e o sucesso desse programa "profetizou o declínio da dicção transatlântica como uma norma da performance" (p. 94). Enquanto os filmes da década de 1930 utilizavam expressões, sotaques e dialetos para demarcar personagens desviantes, na década de 1940 essas expressões diversificadas foram incluídas, começando a descaracterização do padrão clássico da fala. Para analisar esse momento de mudança da fala do cinema, é útil o conceito de "heteroglossia" de Bakhtin, que foi usado originalmente para abordar o romance considerado como "multiforme em estilo e diversiforme em discurso e voz" (apud LEITCH, 2013, p. 91). Como consequência, na década de 1940, tornou-se comum a adaptação de romances em roteiros de filmes falados, pois "seu diálogo heteroglóssico era muito mais flexível e expressivo com uma grande gama de classes sociais e grupos étnicos" (Ibid., p. 97).

A passagem ao naturalismo e ao realismo seguiu influências dos mais variados gêneros. Kozloff (2000) escreve que nas décadas de 1960 e 1970 os diálogos dos filmes americanos soavam mais naturais devido a uma provável influência francesa: "O diálogo 
era notavelmente mais coloquial, menos preocupado com ritmo, menos polido, mais risque e marcado por um ar de improvisação" (p. 23).

Do ponto de vista histórico, o cinema de Hollywood "se caracteriza por um forte desejo de alcançar o realismo. Realizadores se esforçam para colocar na tela uma experiência a qual, tão logo quanto seja possível, a audiência reconheça como natural, comparando com a própria experiência deles" (BUSCOMBE, 2013, p. 157). Nesse "neo-neorrealismo" haveria um retorno àquela tendência do cinema italiano dos anos 1940 e início dos anos 1950 ao retrato do comum, de pessoas anônimas, cujas reações de tipo mais fisiológico que dramático fornecem a principal atração desse gênero, seu "index appeal", ou chamamento indicial (ANDACHT, 2005).

Há uma analogia entre o neorrealismo italiano e as produções brasileiras, como a série $C D H$. Produções ficcionais como esta apresentam ao espectador um mundo que é ao mesmo tempo realista e ficcional, portanto diferente do que acontece no documentário. Depois do sucesso do filme Cidade de Deus ${ }^{6}$, houve uma grande quantidade de produções brasileiras que utilizaram a estética do realismo - a favela como locação e os moradores da comunidade como atores. Guardadas as devidas ressalvas e as propostas narrativas diversas, essa estética realista foi utilizada também na série televisiva Antônia ${ }^{7}$ e no filme denominado Antônia: o filme ${ }^{8}$, assim como nos dois filmes Tropa de elite $e^{9,10}$.

No caso da produção de $C D H$, a favela como locação e a inserção dos moradores como atores intensificam a encenação de um mundo que é ao mesmo tempo realista e ficcional, pois o ambiente e os atores reforçam a hegemonia do signo indicial descrito: o contato do público com a realidade/atualidade pelo retrato do comum e a presença do próprio corpo dos atores/personagens da/na favela, proporcionam uma reflexão sobre a identidade, ou seja, o efeito do index appeal ou chamamento indicial no espectador.

A partir dessas questões, pretende-se reflexionar a respeito dos diálogos do personagem e da questão da entonação sob o aspecto icônico, indicial e simbólico do som e da fala, relacionando os signos da fala dos atores de $C D H$ com o ambiente urbano através do conceito de verossímil.

6 (2002). Dirigido por Fernando Meirelles.

7 (2006 e 2007). Vários diretores.

8 (2006). Dirigido por Tata Amaral.

9 Tropa de Elite (2007) e Tropa de Elite 2: o inimigo agora é outro (2010). Dirigidos por José Padilha.

10 Considerando essa analogia apenas para os personagens moradores da favela, e não para o personagem principal, o Capitão Nascimento, que representa o modelo heroico de Hollywood. 


\section{Possibilidade de análise semiótica da fala}

Pignatari (2004) aponta possibilidades de análise da fala como um signo icônico por tratar-se de material sonoro. O signo icônico é aquele que possui relação direta com o presente, "que está vinculado ao momento da representação" (MARTINO, 2009, p. 118). Portanto, a fala, como ato performático comunicativo, não pode ser dissociada do ser humano que a produz e a emite. Seguindo esse pensamento, Nöth (1995, p. 131) afirma que "na medida em que um signo lingüístico ou padrão sintático é motivado cognitivamente pela estrutura da experiência corpórea, ele é um signo icônico". Essa afirmação corrobora o pensamento de Zumthor (2007) de que a voz não se dissocia do corpo, pois a voz só é plena quando emana sua presença física. Devemos lembrar que a fala é também indicial, pois estabelece relação direta, física entre a pessoa que emite a fala e a própria fala. Também as circunstâncias vitais da pessoa - em nosso caso, o fato de ser ou ter sido um morador da favela - fazem parte dessa relação direta e indicial.

Simões propõe a teoria da iconicidade verbal, que entende o "texto verbal como signo sensível à audição ou à visão, por apresentar características correlatas às detectáveis nos textos ditos não-verbais" $(2009$, p. 59). A teoria apresenta uma análise do signo linguístico "como substância sonora ou gráfica" (Ibid., p. 67), pois dessa forma é possível trabalhar com sua materialidade, seja ela gráfica (escrita) ou sonora (falada). O primeiro postulado da teoria parte do princípio de que o signo verbal possui aspectos próprios de uma imagem, seja ela visual ou sonora, e que essa imagem é plástica, sendo referência de iconicidade (Ibid.). Para a autora, no caso da oralidade considerada como signo icônico sonoro, "a entonação e os acentos produzem a iconicidade diagramática e conduzem o interlocutor na produção da semiose" (Ibid., p. 83), estimulando a criação de uma imagem mental sonora. Portanto, a iconicidade da palavra falada é reforçada e materializada (porque ela também tem aspectos simbólicos e segue as regras da sintaxe e da semântica) pela performance vocal, nas questões relativas à entonação, projeção, contorno melódico da voz etc.

As características das vozes personificam o falante, pois carregam informações biológicas e psicológicas do emissor. Essas características não se relacionam com o sentido textual das palavras ou frases, mas sim com as questões fonéticas, de pronúncia ou dialetos, compartilhadas por determinados grupos, o que aponta para o aspecto indicial. Esses aspectos da entonação são significativos na comunicação, ao passo que elementos fisiológicos e psicológicos podem afetar o significado ou a comunicação da mensagem. A utilização de algum acento prosódico específico pode modificar a mensagem textual. 
A partir dessa perspectiva, é possível refletir sobre a palavra falada também como um signo icônico-indicial, entendendo a iconicidade da palavra falada como parte integrante dos aspectos comunicacionais que pertencem ao código da linguagem. Ao mesmo tempo, entendendo a conexão entre a palavra e o corpo da pessoa que produz a palavra como uma característica que aponta para sua dimensão, ou seu aspecto indicial.

Muitas produções cinematográficas, tanto documentários quanto ficções, utilizam os aspectos fonéticos como elementos fundamentais para a narrativa. É o caso do documentário Morro do Céu ${ }^{11}$, que relata o cotidiano de uma comunidade de ascendência italiana do interior do Rio Grande do Sul, no Brasil. O dialeto dos personagens, em aspectos gramaticais e fonéticos, é um símbolo compartilhado pelo grupo daquela comunidade que é oferecido ao espectador. Ainda, como elemento comum à comunidade, como código compartilhado, o dialeto pode ser considerado um índice do fato de pertencer, de ter nascido, ou de ter sido criado na comunidade Morro do Céu.

Cine Holliúdy"12 começa com o seguinte aviso, em formato escrito: "Vocês vão assistir ao primeiro filme nacional falado em 'cearensês', por isso as legendas". O filme foi um grande sucesso no Ceará por apresentar o dialeto local, com atores locais, compartilhando palavras utilizadas pelos cearenses. Em complemento, o filme possui legendas em português que pretendem traduzir o cearensês. O uso das legendas é irônico, pois parte do princípio de que esse dialeto peculiar não pode ser compreendido por outros brasileiros.

Expandindo o contexto brasileiro, pode-se citar o filme $\mathrm{Her}^{13}$. A narrativa desse filme trata de um homem que se apaixona por um software com uma voz que o personifica, a voz de Scarlett Johansson - que ganhou Oscar de melhor atriz no festival de Cinema de Roma pela interpretação vocal nesse filme. Um ícone midiático feminino foi escolhido para criar uma personagem com personalidade atraente através de uma voz da qual se desconhece o corpo. No filme, a voz desencarnada enfatiza algo central no que diz respeito à iconicidade: a imaginação humana depende dos ícones para introduzir elementos ainda ausentes do mundo real, factual.

\section{A representação do real a partir dos diálogos na produção audiovisual de $C D H$}

No caso de $C D H$, a série propõe uma forma de representar o real baseada em signos de existência, ou índices, que funcionam de forma particular, o que constitui o

11 (2009). Dirigido por Gustavo Spolidoro.

12 (2012). Dirigido por Halder Gomes.

13 (2013). Dirigido por Spike Jonze. 
subgênero do "telerrealismo" (ANDACHT, 2013, p. 8). Tendo os moradores da favela como personagens da história, seus diálogos apresentam marcas vocais, ou convenções sociolinguísticas, compartilhadas por aquele grupo de forma espontânea e, portanto, indicial, pois coexistem no mesmo espaço geográfico, cultural e social. A espontaneidade vocal dos atores é um signo vital para a representação indicial do real da série, pois essa performance vocal produz o efeito estético de ser um elemento da transpiração semiótica indicial. No telerrealismo, os signos se manifestam de forma fisiológica e instintiva, e essas manifestações "remetem de modo inequívoco e plausível a estados de ânimo e emoções corporais, corporizadas" (Ibid., p. 4).

A oralidade considera o aspecto do corpo envolvido na emanação da palavra. Zumthor aponta que a emanação vocal não se encerra nela mesma: "Considero com efeito a voz, não somente nela mesma, mas (ainda mais) em sua qualidade de emanação do corpo e que, sonoramente, o representa de forma plena" (2007, p. 27). Portanto, a corporificação da fala que transparece a partir dos índices corporais verbais emanados na representação é fundamental para que o espectador possa se relacionar com a telerrealidade de $C D H$.

Nas palavras do preparador de elenco Christian Duurvoort (2007), "O fato de os atores pertencerem ao universo retratado facilita o trabalho da direção na medida em que eles correspondem imediatamente à expectativa do público quanto imagem que se tem do lugar a ser retratado". O pertencimento é ressaltado pois podemos perceber na leitura do roteiro de $C D H$ que algumas cenas não contêm falas (como a 24 - "Bando na praia", a 32 - "Bando com o menino Clayton" e a 98 - "Início da guerra"), isto é, são escritas em forma de descrição dos acontecimentos (MORELLI; SOÁREZ, 2008). Esse estilo de roteiro estimula a presença do indicial, ao passo que exige certo grau de improvisação por parte dos atores, deixando transparecer nos personagens as marcas vocais e as qualidades de voz dos atores, criando uma espontaneidade na comunicação.

Dessa forma, o que gera a aparência de espontâneo é tudo aquilo que emerge de modo verossímil na comunicação oral estabelecida entre os personagens de $C D H$. Tal efeito é proveniente do estilo estrutural e dramatúrgico com que a série e o filme foram encenados, mas também das convenções fonéticas e gramaticais utilizadas, que são maneirismos de entoação ou traços sonoros da fala, qualidades que a linguagem cotidiana incorpora de modo natural. Trata-se de padrões motivados "cognitivamente pela estrutura da experiência corpórea" (Nöth, 1995, p. 131) que personalizam o falante a partir de suas experiências de vida. 
No episódio 4 da série, "Uólace e João Vitor"14, existem três momentos em que Laranjinha e Acerola contracenam sozinhos de forma intimista. Um desses momentos é a cena na qual Laranjinha encontra um homem que ele desconfia que possa ser seu pai. A cena começa com os dois amigos caminhando abraçados, desenvolvendo um texto qualquer sobre gêneros musicais. Após essa introdução, mesmo quando o texto emitido é importante para a compreensão da narrativa - como na frase de Laranjinha: "o cara que eu acho que é meu pai, entendeu? Mas eu não tenho certeza" -, a relação de amizade entre os dois amigos continua sendo o ponto marcante da cena. Essa relação é apresentada para a audiência pelas palavras e gestos de Acerola, quando diz que eles realmente são muito parecidos e empurra Laranjinha para falar com o suposto pai, por exemplo. A forma intimista e descontraída da performance vocal de Acerola contém esses maneirismos e traços sonoros da fala, evidenciados pela estrutura material, gerando uma forma peculiar de interação com Laranjinha.

$\mathrm{O}$ filme $C D H$ foi uma produção posterior à série, que desenvolveu uma narrativa sobre o tema comum da paternidade, a partir das experiências individuais de cada personagem: Laranjinha e a busca pelo pai; Acerola e a aceitação do papel de pai do menino Cleyton. A trajetória de Laranjinha é pautada pelos encontros e desencontros com seu progenitor, o que cria movimento e ação para a narrativa, enquanto a situação de Acerola já está estabelecida para o espectador pela presença do menino desde o início do filme. Com foco nesse conflito, a equipe de edição de diálogos do filme optou pela inserção de expressões do menino Cleyton no formato de balbucios, em momentos oportunos do filme (OPOLSKI, 2013). Inseridos em um primeiro momento com o objetivo de reforço narrativo ao conflito da vida adulta, na medida em que desempenham o papel de signos de existência, esses balbucios são exemplos de voz icônica e indicial, pois relembram Acerola de que o filho está ao redor. Além disso, se materializam na figura do filho como um símbolo da vida adulta. Isso acontece nas imagens em que Cleyton está tanto fora quanto dentro de quadro, como na cena final do filme, quando Acerola e Laranjinha caminham de mãos dadas com ele depois de terem deixado o morro.

Por fim, no filme tudo avança em direção ao registro simbólico: o conceito de filiação serve como conclusão lógica geral; trata-se de uma síntese simbólica da presença dos signos icônicos e indiciais. O dialeto é um símbolo ou convenção compartilhada que emerge junto com o ícone (aspecto formal, estético) e o índice (elemento factual de pertencimento a um grupo social específico). A iconicidade da palavra falada é uma forma que se materializa indicialmente em uma circunstância existencial, e assim pode ser compreendida como um símbolo. De modo semelhante, os elementos factuais transformam-se

14 Dirigido por Regina Casé e Fernando Meirelles. Veiculado em 18 out. 2002. 
em símbolos quando a emanação dos índices fisiológicos e aparentemente espontâneos são compreendidos na comunicação da mensagem.

No primeiro episódio da série, "A coroa do imperador"15, quando Acerola cria analogias entre os donos do morro e Napoleão, esses signos são percebidos na performance vocal do personagem: o aspecto formal da oralidade, incluindo dialeto e entonação, junto com as emoções corporais. A explicação começa com "é o seguinte: esse aqui é o morro francês" e continua permeada por respirações profundas e ofegantes - uma característica indicial importante do personagem Acerola quando mais novo. Pequenas escapadas em construções gramaticais corretas - como "que vendia o bagulho "para' todas as 'regiões"' - deixam ainda mais perceptível o icônico-indicial na performance do ator, que é interrompido em momentos como esse pela vaga lembrança de que existe um roteiro. Além disso, é importante notar que a intromissão do roteiro na performance acontece depois de uma gaguejada, um signo de que o ator/personagem seguiria com a própria performance, mas lembra que precisa inserir alguma informação do roteiro, externa a ele.

\section{A representação do real cinematográfico e as relações com o ambiente urbano}

Muitos estudos sobre os diálogos "incorporam a informação fornecida pelo diálogo, mas negligenciam o diálogo como um significante" (KOZLOFF, 2000, p. 6). Entre as funções do diálogo descritas pelo autor, a primeira delas diz respeito a ancorar a diegese e os personagens. A ancoragem pode ocorrer de várias formas: uma delas é utilizar a forma de falar do personagem para localizá-lo como pertencente a um determinado grupo social, como é o caso de $C D H$ : "a linguagem é um dos mais importantes meios pelo qual a identidade é construída, quer seja individual, identidade pessoal, ou de alguma forma maior, como a identidade étnica ou racial" (BUSCOMBE, 2013, p. 157).

Alguns diretores optam por atores não profissionais, com a intenção de aumentar o grau de verossimilhança e credibilidade da história. O neorrealismo italiano apresenta clássicos como Ladrões de bicicleta ${ }^{16} \mathrm{e}$ A terra treme ${ }^{17}$. Neste, os personagens falam em dialeto siciliano, porque de fato eles não sabem falar italiano, "que não é a língua dos pobres", como se fala no filme.

Assim como o neorrealismo italiano, o cinema de Hollywood também teve diretores adeptos à contratação de atores não profissionais - um deles foi John Cassavetes. Ele

15 Dirigido por César Charlone. Veiculado em 15 out. 2002.

16 (1948) Dirigido por Vittorio de Sica.

17 (1948) Dirigido por Luchino Visconti.

$12 \frac{\text { Comunicação \& Inovação, PPGCOM/USCS }}{\text { v. 18, n. } 36(1-16) \text { jan-abr } 2017}$ 
procurava a imperfeição da performance e, por isso, preferia contratar inexperientes para atuar, "com o objetivo de evitar a confiança e a segurança dos atores" (BERLINER, 2013, p. 114) durante as interpretações. De acordo com Berliner (2013, p. 114), “entre a indecisão real dos atores de Cassavetes e a aparente improvisação das falas, seus filmes mesclam arte e realidade como uma mistura incontrolável da identidade própria dos atores com a identidade dos personagens encenados". Cassavetes entendia que uma das melhores formas de fazer o diálogo soar verossímil seria não permitir "identificar as diferenças entre as digressões verbais do ator e as digressões verbais do personagem” (Ibid., p. 111).

Retornando ao exemplo do episódio "A coroa do imperador", logo após a discussão sobre quem teria sido o primeiro dono do "Laderão"18, BB ou Mocotó, os personagens desenvolvem relatos pessoais, apresentados para a audiência de forma contínua, sem um claro limite entre a parte ficcional e a parte documental. No que diz respeito à performance vocal, é difícil ou quase impossível perceber diferenças entre a forma de falar dos atores e a dos personagens. Os efeitos visuais e as legendas, nas quais constam o nome do ator e a idade, são os únicos signos que estabelecem a fronteira entre a ficção e o relato pessoal.

Baseado na teoria da expressão verbal e não verbal da chamada "ordem de interação" de Goffman, Peberdy (2013, p. 208) propõe que "a voz é uma combinação do que é dado [given] (efetuado intencionalmente) e do que é emitido [given off] (não intencional)". Na cena em que o bando do Madrugadão foge do morro, no filme $C D H$, temos um exemplo com falas improvisadas emitidas de maneira intencional junto com índices não intencionais que acompanham sua emissão ${ }^{19}$. A cena é conduzida pelo personagem do Madrugadão de forma enérgica e assertiva. O número de palavras utilizadas pelo personagem é mínimo e são repetidas à exaustão. Apesar da repetição, que poderia levar a audiência ao tédio, a entonação, o ritmo e o contraste de intensidade utilizados pelo personagem produzem uma dinâmica que tem como função gerar a expectativa do público.

Um ponto marcante da performance vocal do Madrugadão acontece no momento em que ele retira o motorista do carro. Essa é a concretização da primeira parte da cena, pois o carro parou assim como a ação previa. Madrugadão vem pronunciando as falas em um crescer de intensidade e, nesse momento, no ápice da resolução da primeira parte da cena, Madrugadão ordena: "desce", antes da coronhada na cabeça do motorista, e essa palavra é emitida com projeção mínima, pouca articulação, boca fechada, com o personagem quase mordendo a própria fala. Uma manifestação indicial de força

18 Na narrativa, o "Laderão" é uma escadaria que liga o asfalto à favela que fica na parte superior do Morro da Sinuca. Essa favela é comandada por Mocotó, que tem interesse em manter o domínio sobre o Laderão para facilitar o acesso dos consumidores de droga à favela.

19 Ver cena 107 do roteiro. 
extrema, que contraria o estereótipo de força criado pela projeção vocal em crescimento contínuo que o próprio Madrugadão usa na cena até então. Ainda nessa mesma cena, devido ao caráter improvisado, é possível perceber o indicial existente nesses personagens, que representam na ficção algo muito próximo de algo não apenas conhecido intelectualmente, mas vivido por eles.

Durante a performance vocal, na medida em que a linha que separa o ator do personagem é minimizada ou deixa de existir, o ambiente vocal vivenciado pela audiência diariamente como algo factual através da mídia, especificamente dos telejornais, é representado no audiovisual ficcional. A partir de então, de forma cíclica, o diálogo cinematográfico se utiliza do ambiente diário do ator e da audiência, assim como serve de estímulo para criar novas performances vocais e linguagens urbanas.

\section{Considerações finais}

A preocupação de criar um discurso verossímil é bem mais antiga do que a verossimilhança do cinema: sempre o que foi e é expressado em qualquer meio resulta de uma mistura da liberdade criativa e da contrição das regras do gênero em questão. Hoje soma-se a essa tensão tradicional uma procura obstinada pela representação da realidade em diversos gêneros e meios - uma tendência que vai muito além do tradicional filme documentário.

A produção audiovisual brasileira utilizou essa técnica em inúmeras produções na década passada, pois essa representação do real, por exemplo, o telerrealismo da série $C D H$, aproxima o espectador da produção, estimulando o desejo e a fantasia do público de uma maior identificação ou proximidade afetiva com a narrativa e com os personagens.

Na produção de $C D H$, tanto a série quanto o filme utilizam a materialidade vocal indicial compartilhada pelos atores, que só foi possível pelo fato de ambos compartilharem, terem crescido e vivido longo tempo na mesma cultura, no mesmo espaço geográfico e posição social. Todas essas características contribuem para a produção natural da transpiração semiótica indicial. Mesmo com o ensaio e a encenação, que fazem parte central de tais produções artísticas e comerciais, o elemento indicial escoa através do roteiro e das instruções da performance. A fala, nesse caso, é um elemento narrativo e dramático que gera identificação entre o espectador e a produção audiovisual, ou ao menos um tipo de relação "forte", realista, que é específica dessas criações, pois é naturalmente emergente da comunicação oral estabelecida entre os personagens de $C D H$.

As falas dos personagens são signos icônicos, indiciais e simbólicos, que por suas manifestações e características personalizam o falante. Essas características têm relação 
qualitativa, material com o sentido textual e convencional das palavras ou frases, porque o icônico e o indicial se relacionam com as questões fonéticas, de pronúncia ou dialetos, usados e compartilhados cotidianamente por determinados grupos. Portanto, as convenções fonéticas são qualidades da pronúncia do ator falante dessas produções e, como tais, podem ser consideradas, por um lado, ícones, na medida em que possuem relação qualitativa e idiossincrática com a fala e o produtor do som; e, por outro, índices, ao passo que emergem do corpo a partir de situações concretas, originárias da experiência de um grupo. Ao final, podem ser comunicadas em símbolos quando são compreendidas como estrutura social e cultural compartilhada e resultante de toda a relação.

Concluindo, na produção de $C D H$, a fala dos personagens é imprescindível para gerar verossimilhança, pois o verossímil é criado a partir da expressão verbal concreta e materializada dos personagens centrais. Nesses casos, os signos verbais, do ponto de vista fonético, o sotaque e o dialeto, são, enquanto signos, inseparáveis do corpo dos falantes e do lugar no mundo onde eles moram ou moravam. Portanto, na minissérie e no filme $C D H$, estabelece-se uma relação semiótica existencial ou indicial com o ambiente urbano, na medida em que representa um mundo específico e problemático na sociedade brasileira através da língua portuguesa e das evidências sonoras ou fonéticas de pertença a esse lugar. A linguagem do grupo é representada de modo audiovisual pela performance vocal, que contribui para transformar a linguagem urbana em forma de retroalimentação. Ao mesmo tempo que a forma de falar de um grupo é representada no âmbito televisual e cinematográfico, a audiência introduz a forma de falar do grupo representado na conversação diária, estabelecendo dessa forma um ciclo evolutivo que é próprio do crescimento dos signos no mundo.

\section{Referências}

ANDACHT, F. Duas variantes da representação do real na cultura midiática: o exorbitante Big Brother Brasil e o circunspeto Edifício Master. Contemporânea, Salvador, v. 3, n. 1, p. 95-122, 2005.

Os signos do real no cinema de Eduardo Coutinho. Devires, Belo Horizonte, v. 4, n. 2, p. 42-61, 2007.

Análisis de un episodio de la miniserie Cidade dos homens como una fábula indicial. Situarte, Maracaibo, v. 8, n. 14, p. 7-17, enero/jun. 2013.

BERLINER, T. Killing the writer: movie dialogue conventions and John Cassavetes. In: JAECKLE, J. Film dialogue. New York: Columbia University Press, 2013.

BUSCOMBE, E. "They will speak in our language": Indian speech in western movies. In: JAECKLE, J. Film dialogue. New York: Columbia University Press, 2013. 
DUURVOORT, C. Cidade dos homens (2006). 2007. Disponível em: $<$ http://bit.ly/2kWkzQk $>$. Acesso em: 13 dez. 2015.

INSTITUTO HUMANITAS UNISINOS. Cidade dos homens: a realidade do dia-a-dia das favelas cariocas. Entrevista especial com Paulo Morelli. 2007. Disponível em: <http://bit.ly/2kzFKXv>. Acesso em: 9 dez. 2015.

JAMES, W. Pragmatism: a new name for some old ways of thinking. London: Longmans, Green and Co, 1907.

KOZLOFF, S. Overhearing film dialogue. Berkeley; Los Angeles: University of California Press, 2000.

LEITCH, T. You talk like a character in a book: dialogue and film adaptation. In: JAECKLE, J. Film dialogue. New York: Columbia University Press, 2013.

MARTINO, L. M. S. Teoria da comunicação. Rio de Janeiro: Vozes, 2009.

METZ, C. O dizer e o dito no cinema: ocaso de um verossímil? In: . A significação no cinema. São Paulo: Perspectiva, 2007. p. 225-243.

MORELLI, P; SOÁREZ, E. Cidade dos homens. São Paulo: Imprensa oficial do estado de São Paulo, 2008. Disponível em: <http://bit.ly/2kbZWeL>. Acesso em: 13 dez. 2015.

NÖTH, W. Panorama da semiótica: de Platão a Peirce. São Paulo: Annablume, 1995.

OPOLSKI, D. R. Introdução ao desenho de som. João Pessoa: UFPB, 2013.

PEBERDY, D. Male sounds and speech affectations: voicing masculinity. In: JAECKLE, J. Film dialogue. New York: Columbia University Press, 2013.

HARTSHORNE, C.; WEISS, P.; BURKS, A. (Eds.). Collected papers of Charles Sanders Peirce. Cambridge, MA: Harvard University Press, 1931-1958.

PIGNATARI, D. Semiótica e literatura. São Paulo: Ateliê Editorial, 2004.

SCOTT, A. O. How real does it feel? The New York Times, New York, 9 dez. 2010. Disponível em: <http:// nyti.ms/1BBumif>. Acesso em: 30 ago. 2015.

. "True Story", "The Jinx" and serving up truth with the imagination. The New York Times, New York, 22 abr. 2015. Disponível em: <http://nyti.ms/2lvYu7N>. Acesso em: 13 dez. 2015.

SIMÕES, D. Iconicidade verbal: teoria e prática. Rio de Janeiro: Dialogarts, 2009.

ZUMTHOR, P. Performance, recepção, leitura. São Paulo: Cosac Naify, 2007. 